\title{
Review of Chinese species of genus Xenovarta Viraktamath (Hemiptera: Cicadellidae: Deltocephalinae: Scaphytopiini) with description of a new species
}

\author{
YANI DUAN ${ }^{1,2} \&$ YALIN ZHANG $^{1,3}$ \\ ${ }^{1}$ Key Laboratory of Plant Protection Resources and Pest Management of Ministry of Education, Entomological Museum, Northwest A \\ \& F University, Yangling, Shaanxi Province 712100, China. \\ ${ }^{2}$ School of Plant Protection, Anhui Agricultural University, Hefei, Anhui Province 230036, China. \\ ${ }^{3}$ Corresponding author. E-mail: yalinzh@nwsuaf.edu.cn
}

\begin{abstract}
The Chinese leafhopper species of the genus Xenovarta Viraktamath are reviewed, one new species Xenovarta longicornis sp. n. is described and a key is provided for the six Oriental species of the genus.
\end{abstract}

Key words: Taxonomy, Homoptera, Auchenorrhyncha, leafhopper, Oriental Region, China

\section{Introduction}

The genus Xenovarta was established by Viraktamath (2004) in the deltocephaline leafhopper tribe Scaphytopiini, for five Oriental species, including its type species Xenovarta acuta Viraktamath. The genus is one of several placed in the Varta-Stymphalus complex by Viraktamath (2004) all of which have striking orange to red markings (see Plate I). It was distinguished from other members of the complex in the male by the fused plates and valve, articulated aedeagus and connective and well developed subapical lobe of the style with a rather elongate rugulose apophysis.

In the present paper the three Chinese species of the genus, including one new species, are described and illustrated and a key to all species is provided. Specimens are deposited in Entomological Museum of Northwest A \& F University (NWAFU) and Sun Yat-Sen University (SYU). Morphological terminology follows Oman (1949) and Zhang (1990).

\section{Taxonomy}

\section{Xenovarta Viraktamath}

Xenovarta Viraktamath, 2004: 23. Type species: Xenovarta acuta Viraktamath

Distribution. China, Indo China (Vietnam, Laos, Cambodia) and the Pacific (Sabah).

\section{Key to species of Xenovarta Viraktamath}

1 Face tumid (see Viraktamath, 2004, Fig. 163); aedaegal shaft cylindrical, without processes, with a large subapical gonopore (see Viraktamath, 2004, Figs 168, 169) cylindrica Viraktamath

- Face concave in profile (Fig. 2B); aedeagal shaft either compressed without processes or with processes .................2 Males

2 Aedeagal shaft asymmetrical (Figs 1F, 2F) 3 
- $\quad$ Aedeagal shaft symmetrical (Fig. 3G)

5

3 Aedeagus with pair of apical processes (Fig. 2H)

4

- $\quad$ Aedeagus with well-developed dorsal process near midlength (Fig. 1G)

longicornis sp. $\mathbf{n}$.

4 Male pygofer without oblique sclerotized band, caudo-dorsal angle without a triangular lobe (Fig. 2C); subgenital plates moderately long with small sclerotized dorsal pads (Fig. 2D); aedeagal shaft twisted at mid length, both processes of aedeagal shaft curved (Fig. $2 \mathrm{H})$. ankusha Viraktamath
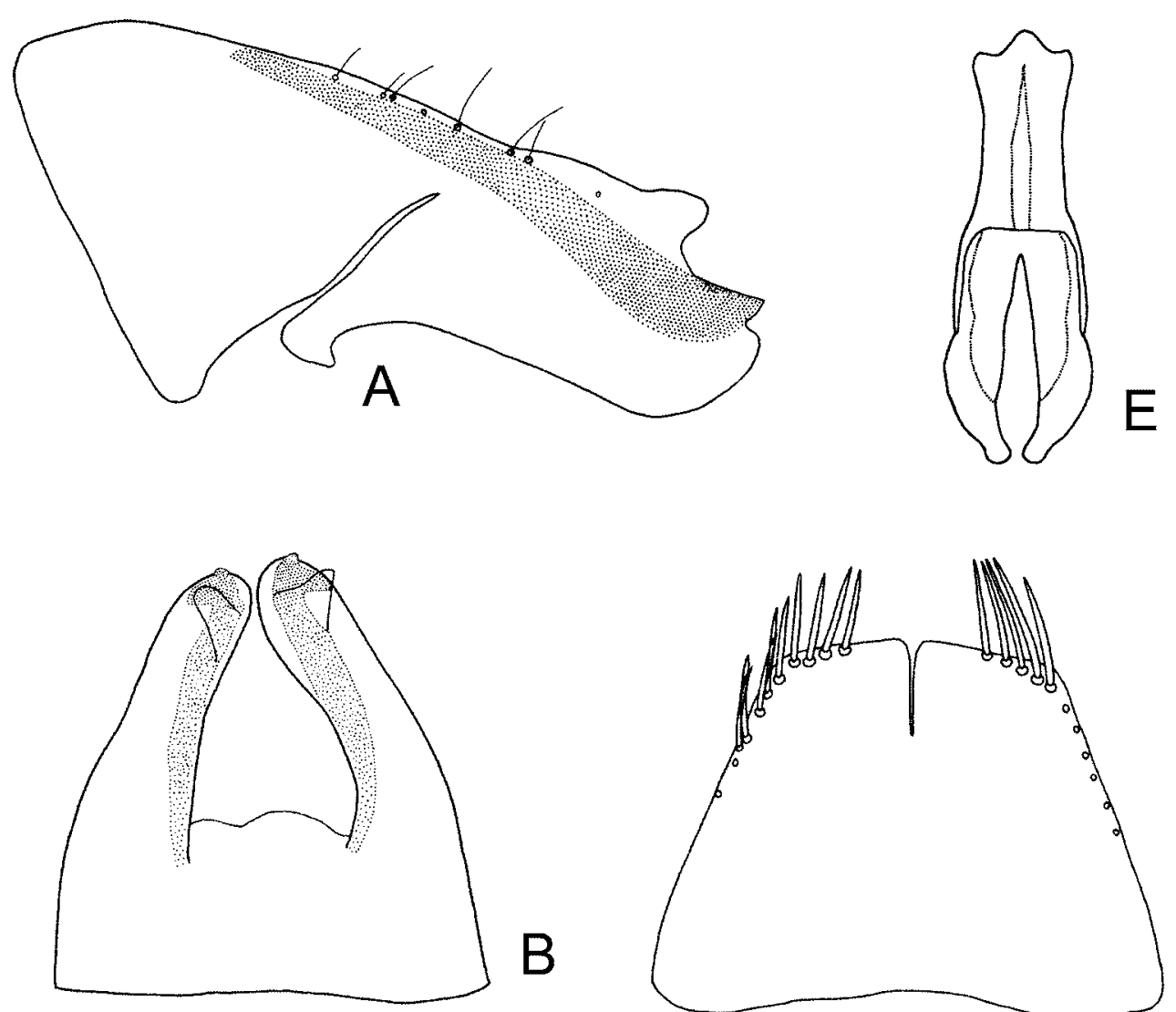

B
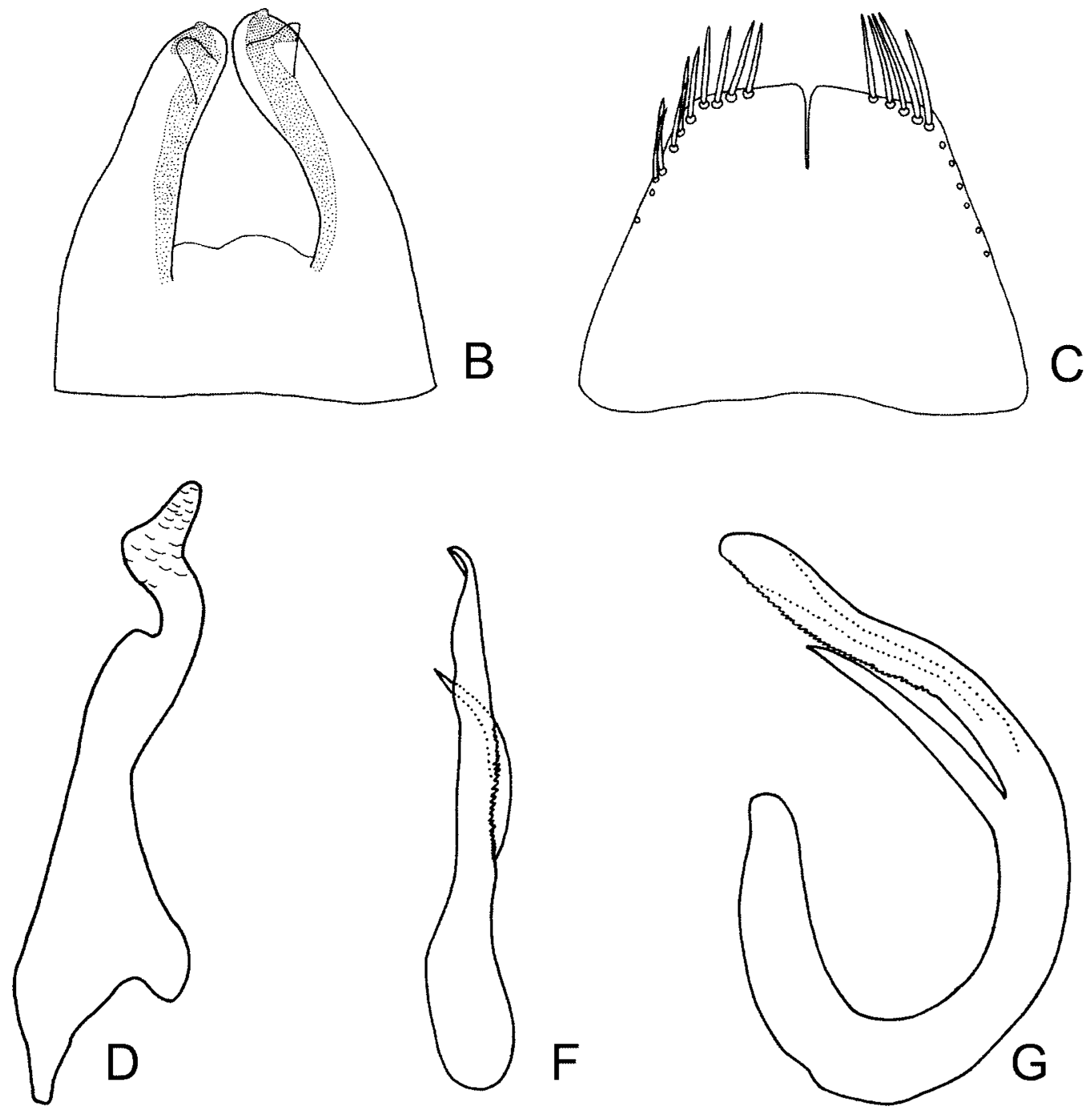

FIGURE 1. Xenovarta longicornis sp. n. A: male pygofer, lateral view; B: male pygofer, dorsal view; C: valve and subgenital plates; D: style; E: connective; F: aedeagus, ventral view; G: aedeagus, lateral view. 
- Male pygofer with an oblique sclerotized band across the length and caudo-dorsal angle with a triangular lobe (see Viraktamath, 2004, Fig. 170); subgenital plates very short with extensive caudo-lateral marginal sclerotized pad (see Viraktamath, 2004, Fig. 171); aedeagal shaft not twisted at mid length, one process of shaft pointed, other hooklike (see Viraktamath, 2004, Fig. 175, 176). .. harpago Viraktamath

5 Aedeagal shaft with pair of distally hooked basal processes (Figs 3G, 3H)...... acuta Viraktamath

- Aedeagal shaft without such processes, distal part foot-shaped (see Viraktamath, 2004, Fig. 148)

compressa Viraktamath
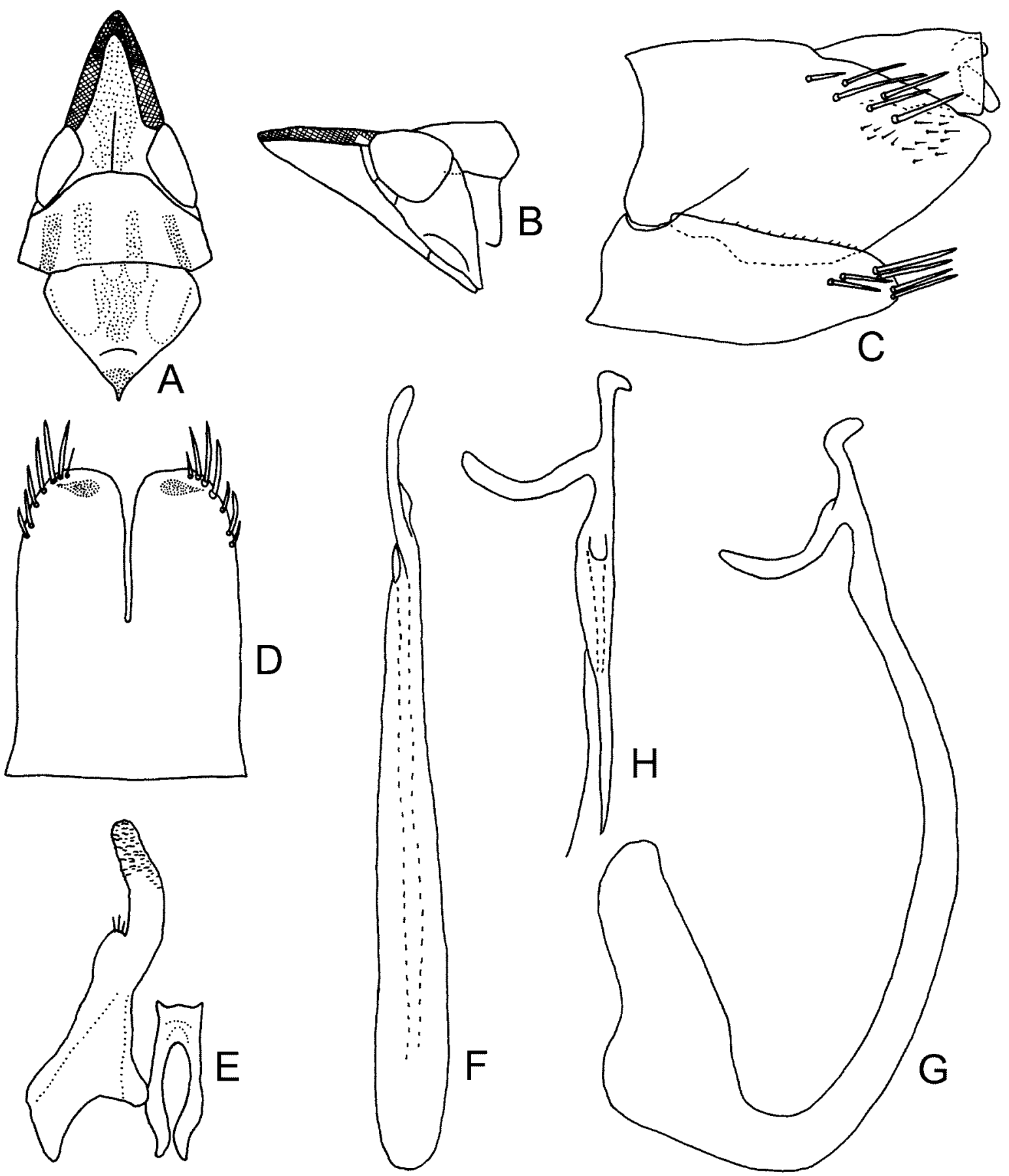

FIGURE 2. Xenovarta ankusha Viraktamath, 2004 (after Viraktamath 2004) A: head and thorax, dorsal view; B: head and thorax, lateral view; C: male genital segment, lateral view; D: valve and subgenital plates; E: style and connective; F $\& \mathrm{H}$ : different views of aedeagal shaft; G: aedeagus, lateral view. 


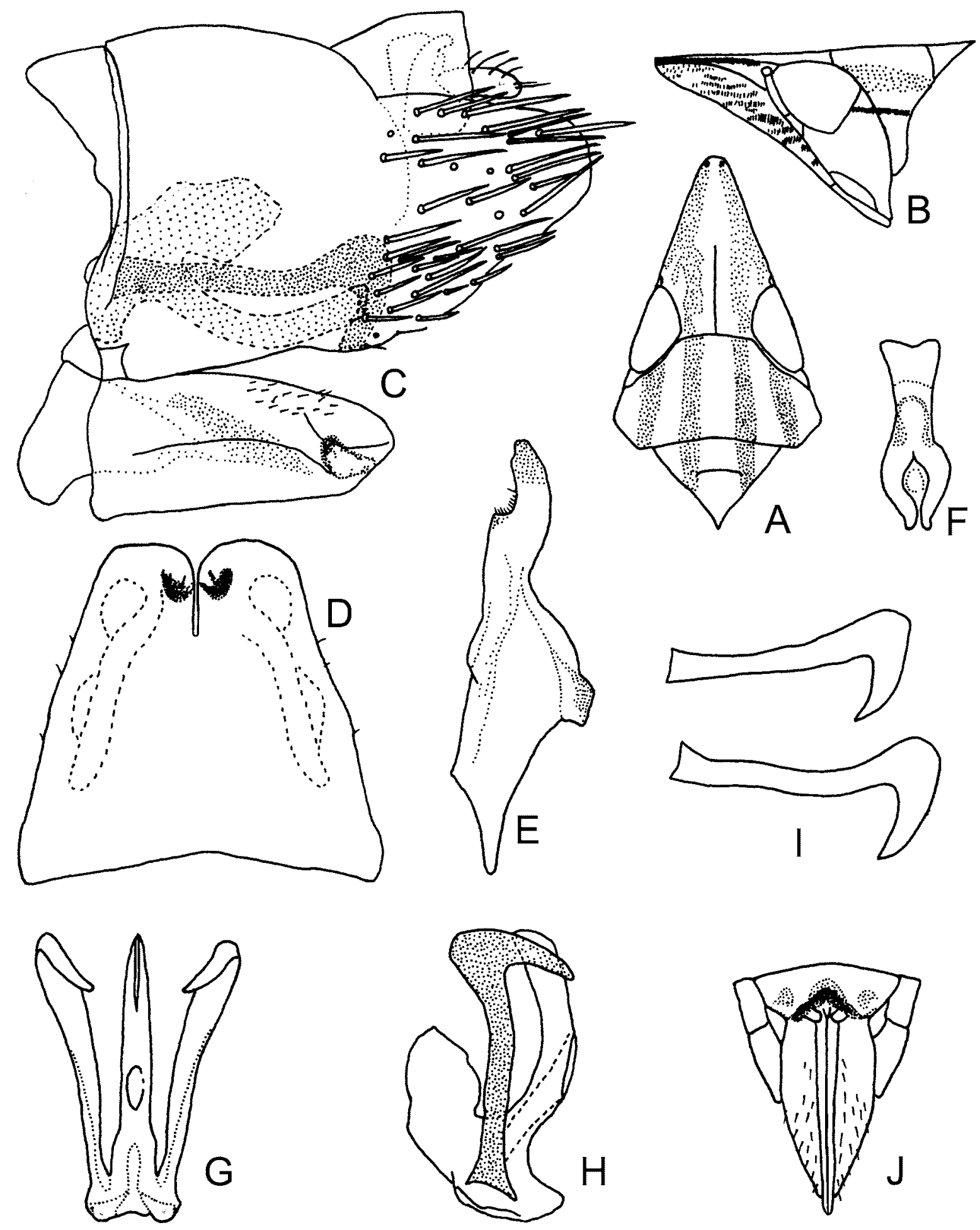

FIGURE 3. Xenovarta acuta Viraktamath, 2004 (after Viraktamath 2004) A: head and thorax, dorsal view; B: head and thorax, lateral view; C: male genital segment, lateral view; D: valve and subgenital plates; E: style; F: connective; G: aedeagus, dorsal view; H: aedeagus, lateral view; I: variation in lateral processes of aedeagus; J: apex of female abdomen, ventral view.

\section{Xenovarta longicornis sp. $\mathbf{n}$.}

(Fig. 1; plate I: $\mathrm{C}-\mathrm{G}$ )

Dark bluish green; margins of vertex anterior to eyes bright red; median area of frontoclypeus, basal areas of 
clypellus and lora ochraceous; pronotum with two red stripes on either side of median line; scutellum laterally and basally brownish ochraceous; forewing with red stripes as in plate I: G, apical area brownish hyaline.
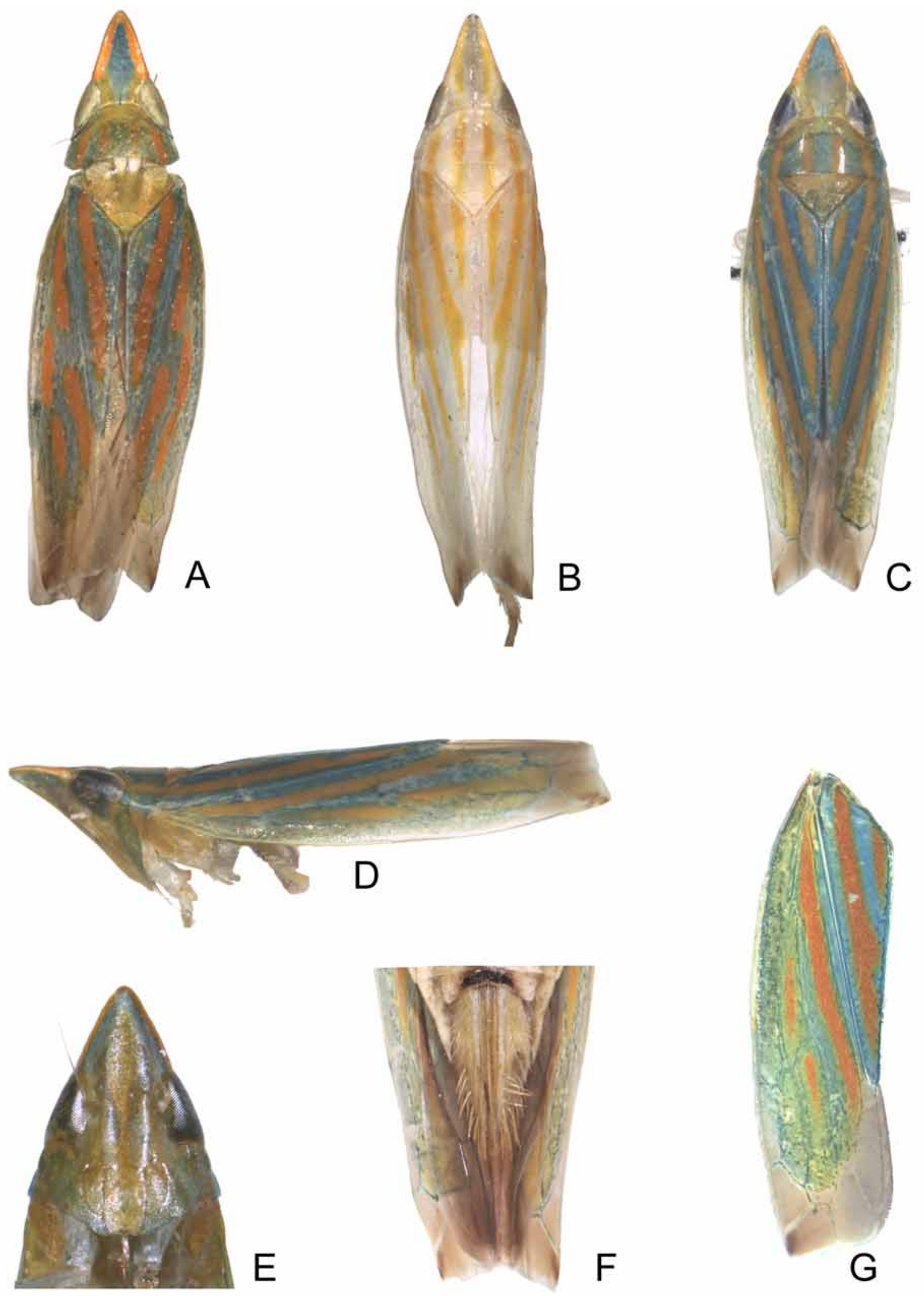

PLATE I. A: Xenovarta ankusha Viraktamath, 2004, dorsal habitus; B: Xenovarta acuta Viraktamath, 2004, dorsal habitus; C-G: Xenovarta longicornis sp. n., C: dorsal habitus; D: lateral habitus; E: face; F: apex of female abdomen; G: forewing. 
Vertex acutely triangularly produced in front of eyes, about $2.5 \mathrm{x}$ as long as interocular width, $1.7 \mathrm{x}$ as long as pronotum, lateral margins sharp, carinate, upturned.

Male genitalia. Pygofer elongate, dorsal margin strongly inclined ventrally, with sclerotised submarginal band from base of anal tube extending caudally and terminating in short triangular process at ventroposterior margin; without macrosetae. Valve fused to subgenital plates the latter with uniseriate row of macrosetae. Style apophysis footlike, distally rugulose. Connective narrowly Y-shaped, with arms about as long as stem. Aedeagal shaft asymmetrical, strongly arched in lateral aspect, slightly laterally compressed with welldeveloped dorsal process near midlength, gonopore apical.

Female genitalia. Female seventh sternum straight medially on posterior margin.

Measurements. Male: $5.6-5.9 \mathrm{~mm}$, Female: $6.3-6.5 \mathrm{~mm}$.

Material examined. Type. Holotype: $\sigma^{x}$, China, Hainan Prov., Diaolue Mountain, 02.vi.2007, coll. Duan

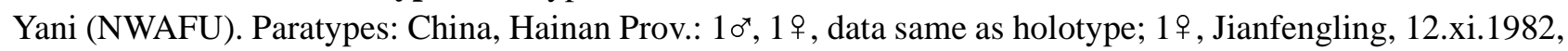
coll. Chen Xiaomi (SYU); 1우, Jianfengling, 29.viii.2002, coll. Wang Zongqing (NWAFU); $10^{\star}$, Limu Mountain, altitude: 665m, 13.viii.2009, coll. Gaoxia (NWAFU).

Remarks. This species is similar to Xenovarta cylindrica Viraktamath, but can be distinguished by the foot-shaped apophysis of the style and by the aedeagus having a well-developed dorsal process near midlength.

Etymology. The name of this species is based on the well-developed dorsal process of the aedeagus.

\section{Xenovarta ankusha Viraktamath}

(Fig. 2; plate I: A)

Xenovarta ankusha Viraktamath, 2004: 26, figs 48, 154-162.

This species have been described in detail by Viraktamath (2004).

Material examined. China: $1 \sigma^{\star}$ (Holotype), Guangdong Prov., Guangzhou City, Fengkai, Heishiding, 08.viii.1986, coll. Zhang Yalin \& Xiang Hui (NWAFU); $10^{\star}$, Guangxi Prov., Shiwandashan Mountain, 29.xi.2001, coll. Wang Zongqing (NWAFU).

Distribution. China (Guangdong, Guangxi).

\section{Xenovarta acuta Viraktamath}

(Fig. 3; plate I: B)

Xenovarta acuta Viraktamath, 2004: 24, figs 45, 134-143.

This species have been described in detail by Viraktamath (2004).

Material examined. China: $20^{x} o^{x}, 1$ 우 (Paratype), Hunan Prov., Hengshan Mountain, 08.viii.1985, coll. Zhang Yalin \& Chai Yonghui (NWAFU); 1 오 (Paratype), Fujian Prov., Jianyang Dazhulan, 27.x.1974, coll. Yang Jikun (NWAFU).

Distribution. China (Fujian, Hunan, Hong Kong).

\section{Acknowledgements}

We express our sincere thanks to M. D. Webb, Department of Entomology, The Natural History Museum, Cromwell Road, South Kensington, London, UK and Dr. C. A. Viraktamath, Department of Entomology, University of Agricultural Sciences, Bangalore, India for revising the manuscript while visiting Northwest A \& F University. We would like to acknowledge Professor Pang Hong in Sun Yat-Sen University for arranging the loan of specimens. This study is supported by the National Science Foundation of China (30470250, 
30499341) and the Pilot Project of Standardized Curation, Data Integration and Resource Sharing of Zoological Collections (2005DKA21402).

\section{Reference}

Oman, P.M. (1949) The Nearctic leafhoppers (Homoptera: Cicadellidae) A generic classification and check list. Memoirs of the Entomological Society of Washington, 3, 1-253, pls. 1-44.

Viraktamath, C.A. (2004) A revision of the Varta-Stymphalus generic complex of the leafhopper tribe Scaphytopiini (Hemiptera: Cicadellidae) from the Old World. Zootaxa, 713, 1-47.

Zhang, Y.L. (1990) A taxonomic study of Chinese Cicadellidae (Homoptera). Tianze Press, Yangling, Shaanxi, China, $218 \mathrm{pp}$. 